\title{
Study of Stress Distribution in Maxillary Anterior Region during True Intrusion of Maxillary Incisors using Finite Element Methodology
}

\author{
Sagar S Padmawar, Anup Belludi, Amit Bhardwaj, Vinay Vadvadgi, Rajiv Saini
}

\begin{abstract}
Introduction: One of the major challenges of fixed clinical orthodontics is the correction of deep overbite. Miniscrew implants are ideally suited for absolute intrusion because they make it possible to apply light continuous forces of known magnitudes without producing any reciprocal reactionary effect on posterior teeth. The purpose of this finite element method (FEM) study was to evaluate and compare the stresses generated in maxillary anterior region during absolute en masse intrusion of six maxillary teeth using mini-implants at strategic locations.
\end{abstract}

Materials and methods: Finite element model was generated using FEM software and on the same model finite element analysis was carried out to study the stress distribution in maxillary anterior region during true incisor intrusion.

Results: Soft bone and hard bone showed significantly high stress distribution in maxillary anterior region.

Conclusion: Stresses on the teeth, soft bone and hard bone, were concentrated more on and near the central incisors as compared to lateral incisors. This was probably because the point of force application was between the central incisors and away from the lateral incisors.

Keywords: True intrusion, Finite element analysis, Miniimplants and stress distribution.

How to cite this article: Padmawar SS, Belludi A, B hardwaj A, Vadvadgi V, Saini R. Study of Stress Distribution in Maxillary Anterior R egion during True Intrusion of Maxillary Incisors using Finite Element Methodology. Int J Experiment Dent Sci 2012;1(2):89-92.

\section{Source of support: Nil}

Conflict of interest: None

\section{INTRODUCTION}

$V$ arious types of orthodontic movement have been reported to increase the risk of root resorption one of which is intrusion. Different types of orthodontic tooth movement may produce different mechanical stress at varying locations within the root. Thus, the measurement of stress in vivo is difficult and so development of an effective model for this system is a worthy goal. ${ }^{1}$

In orthodontics, deep bite correction is a major challenge. In most instances this correction is produced by the extrusion of posterior teeth, or a combination of anterior intrusion along with posterior extrusion, which is undesirable in vertical growers. ${ }^{2}$ Orthodontic tooth movement has al ways been limited to action-reaction reciprocal force mechanics for anchorage control. ${ }^{3}$
Miniscrew implants (M SIs) used as fixed anchorage devices give orthodontists increased potential for versatile mechanotherapy resulting in favorable treatment outcome. Perhaps most importantly, they help to reduce patient compliance during treatment, like use of headgears for anchorage preservation. M SIs are especially well suited for intruding teeth because they make it possible to apply light continuous forces of known magnitudes without producing any reactionary reciprocal effect on posterior teeth. B etter control of the forces could diminish apical root resorption often associated with intrusive movements.

It is believed that root resorption is result of a complex combination of individual biology and the effects of mechanical forces in orthodontics. Loss of apical root material is unpredictable and when extending into dentin, is irreversible. Histological studies reported a high incidence, whereas clinical studies reveal a more varied incidence. In 1856, Bates was the first to discuss root resorption of permanent teeth. ${ }^{4}$

The first descriptive FEA study of orthodontic tooth displacement and stress magnitudes was conducted by Tanne et al. Finite element method (FEM) has been used successfully to model the application of forces to singletooth systems. A lveolar bone loss was shown to lower the center of resistance of the tooth and al ter the stress patterns on the root. Similar changes were observed in altering root length. FEM was also used to show that areas of bone remodeling in vitro corresponded with the same areas in vivo. ${ }^{5}$ The FEM is a highly precise technique used to analyze structural stress. FEM has many advantages over other methods (such as the photoelastic method), highlighted by the ability to include heterogeneity of tooth material and irregularity of the tooth contour in the model design and the relative ease with which loads can be applied at different directions and magnitudes for a more complete analysis. Finite element analysis has been used in dentistry to investigate a wide range of topics, such as the structure of teeth, ${ }^{6-9}$ biomaterials and restorations, ${ }^{10-12}$ dental implants, ${ }^{13-16}$ and root canals.

In orthodontics, FEM has been used successfully to model the application of forces to single tooth systems. Alveolar bone loss was shown to lower the center of resistance of the tooth and alter the stress patterns on the root. ${ }^{17-19}$ 
The purpose of this FEM study was to investigate stress distribution in the maxillary anterior region during absolute intrusion using mini-implants at strategic locations.

\section{MATERIALS AND METHODS}

For the study, one finite element model was generated. This model is the replica of adult human maxilla. The model consisted of periodontal ligament, al veolar bone and all the teeth except third molars. The bracket system simulated was M BT extraction series bracket system from 3M U nitek $(0.22$ Slot) and the archwire was of $21 \times 25$ stainless steel consisting of two attachments between central and lateral incisors bilaterally.

A three-dimensional (3D) quantitative analysis requires some mathematical method, making use of a model accurate both in anatomy and physical characteristics, and along with the use of a computer, which has become an indispensable aid as far as 3D analyses are concerned.

Construction of the geometric model: Mathematical models represented the biological properties of the teeth and the periodontium. This was represented in terms of points (grids), lines, surfaces (patterns) and volume (hyperpatches). In this study a 3D computed tomographic (CT) scan of adult maxilla was taken. The software used for geometric modeling was ANSY S Workbench 11.

$M$ aterial property data representation: The different structures involved in this study include teeth, the periodontal ligament and alveolar bone. Each structure has specific material property. The material properties used here were derived by M cGuinness and were also used in finite element studies done by Tanne. ${ }^{5,20}$

Defining the boundary condition: The boundary conditions are defined to simulate constrained model and to prevent it from free body motion. The nodes attached to the area of the outer surface of the bone are fixed in all directions to avoid free body movement of the tooth.

Loading configuration: The point of force application was from the single mid implant to the attachment on the wire $(21 \times 25$ SS) between central incisors (Fig. 1).

\section{RESULTS}

Following results were obtained and tabulated (Figs 2 to 4 and Table 1).

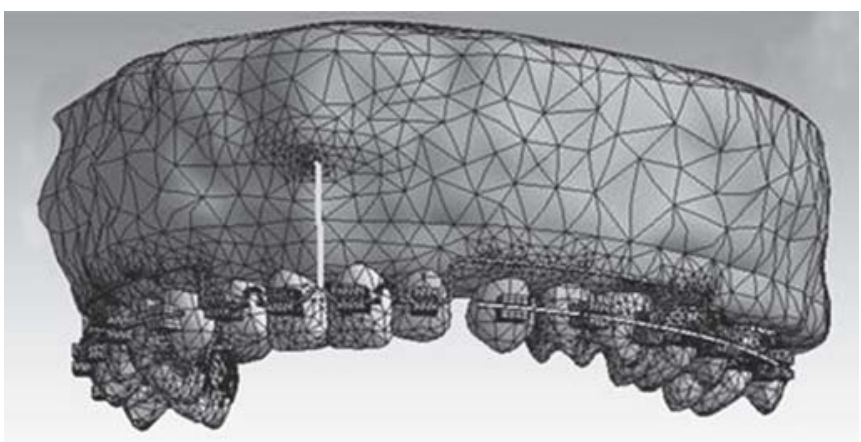

Fig. 1: Point of force application on the model from the mid-implant to the attachment on the wire between the central incisors

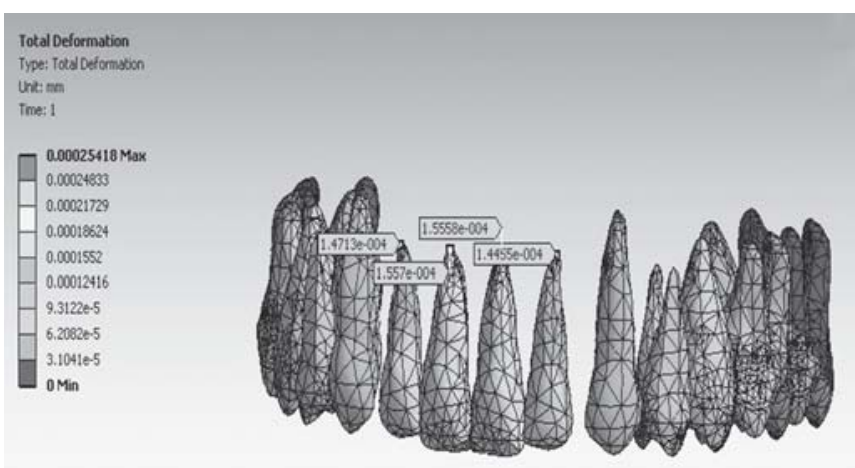

Fig. 2: The total deformation on the tooth

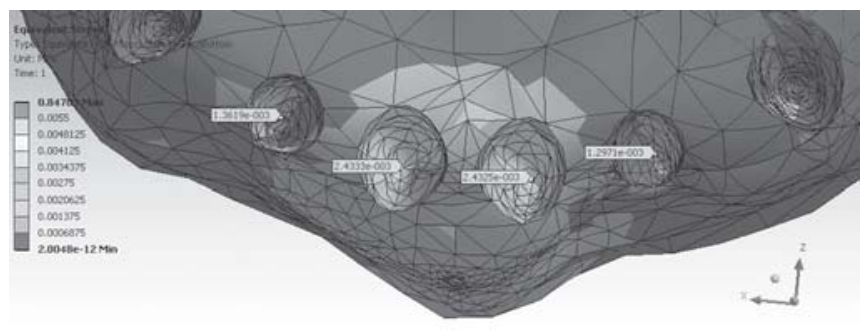

Fig. 3: Stress distributions in the soft bone

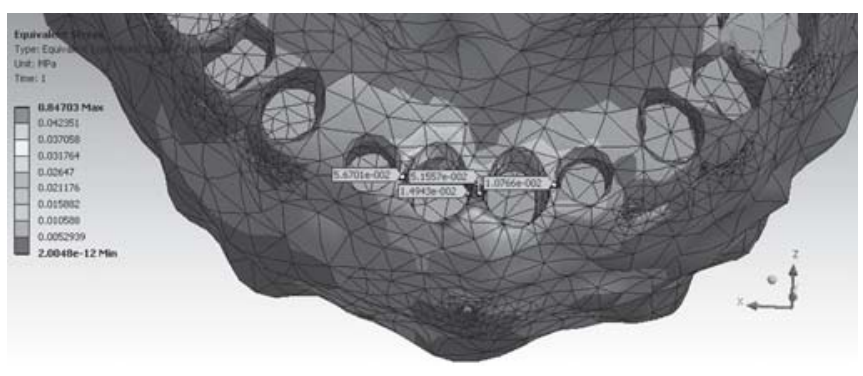

Fig. 4: Stress distribution in the hard bone

\begin{tabular}{llccc}
\multicolumn{5}{c}{ Table 1: Stresses generated in and around the maxillary incisors } \\
S. no. & Location & Stress on soft bone (MPa) & Stress on hard bone (MPa) & Deformation on tooth (mm) \\
\hline 1 & Left central incisor & $2.432 \mathrm{e}-3$ & $5.1557 \mathrm{e}-2$ & $1.557 \mathrm{e}-4$ \\
2 & Left lateral incisor & $1.297 \mathrm{e}-3$ & $1.0766 \mathrm{e}-2$ & $1.4713 \mathrm{e}-4$ \\
3 & Right central incisor & $2.433 \mathrm{e}-3$ & $1.4943-2$ & $1.5558 \mathrm{e}-4$ \\
4 & Right lateral incisor & $1.3619 \mathrm{e}-3$ & $5.670 \mathrm{e}-2$ & $1.4455 \mathrm{e}-4$ \\
\hline
\end{tabular}


Study of Stress Distribution in Maxillary Anterior Region during True Intrusion of Maxillary Incisors

\section{DISCUSSION}

The FEM enables the investigation of biomechanical issues involved in orthodontic treatment. FEM has many advantages over other methods (such as the photoelastic method), highlighted by the ability to include heterogeneity of tooth material and irregularity of the tooth contour in the model design and the relative ease with which loads can be applied at different directions and magnitudes for a more complete analysis. ${ }^{21}$

The present study on finite element model analysis was carried out to evaluate and observe the stresses generated and distributed during true intrusion of the maxillary incisors.

Our study on finite element model of intrusion using single mid implant in the maxillary anterior region for intrusion of incisors, showed variable stress distribution on the teeth, soft bone and hard bone. However, the stresses in the apical areas of all the teeth showed significantly lesser amount of stress compared to the crown areas.

Research shows that comprehensive orthodontic treatment causes increased incidence and severity of root resorption and that the heavy forces are particularly harmful. Heavy force application produces more significant orthodontically induced inflammatory root resorption than light force application. ${ }^{22}$

Our study does not show any significant stress distribution at the apical area of the teeth at the initial point of force application. However, the amount of intrusion and the duration is significantly correlated to the amount of stress generated at the apices to initiate apical root resorption. As it can be assumed that the range of stresses exerted by the blood in the capillary vessels $\left(0.0026 \mathrm{~N} / \mathrm{mm}^{2}\right)$ helps us to predict the onset of bone remodeling. ${ }^{21}$

\section{CONCLUSION}

A mong all the orthodontic moments, intrusion is the most detrimental in orthodontics. It is well-established that these forces generate stress which cause changes on the tooth structure and the surrounding periodontium.

The FEM is highly precise technique used to analyze structural stresses. Over the years FEM has been used successfully used in orthodontics to simulate various orthodontic tooth moments and stress distribution patterns.

The purpose of this study was to evaluate the stress distribution in maxillary anterior region during intrusion of incisors with single mid implant. However, our study showed that the stresses were distributed more evenly on the crown and root structure, but the changes in the tooth structure at the apex leading to root resorption and bone remodeling can be attributed to the capillary pressure changes when it exceeds $0.0026 \mathrm{~N} / \mathrm{mm}^{2}{ }^{23}$

\section{REFERENCES}

1. Rudolph DJ, Willes PM G, Sameshima GT. A finite element model of apical force distribution from orthodontic tooth movement. A ngle Orthod 2001;71(2):127-31.

2. Burstone $C R$. Deep overbite correction by intrusion. A m J Orthod 1977 J ul; 72(1):1-22.

3. Ohnishi $H$, Y agi T, Y asuda Y, Takada K. A mini-implant for orthodontic anchorage in a deep overbite case. Angle Orthod 2005; 75(3):444-52.

4. M assler $M, M$ alone $A J$. Root resorption in human permanent teeth: A roentgenographic study. A m J Orthod Dentofacial Orthop 1954 A ug;40(8):619-33.

5. Tanne K, Bantleon HP. Stress distribution in the periodontal ligament induced by orthodontic forces. U se of finite-element method. Inf Orthod K eiferorthop 1989;21(2):185-94.

6. Rubin C, K rishnamurthy N, Capilouto E, Y i H. Stress analysis of the human tooth using a three-dimensional finite element model. J Dent Res 1983;62:82-86.

7. Toparli M, Gokay N, A ksoy T. A nalysis of a restored maxillary second premolar tooth by using three-dimensional finite element method. J Oral Rehabil 1999; 26:157-64.

8. M agne $P$, V ersluis A, D ouglas W H. Rationalization of incisor shape: Experimental numerical analysis. J Prosthet Dent 1999;81:345-55.

9. Darendeliler $\mathrm{S}$, Darendeliler $\mathrm{H}, \mathrm{K}$ inoglu T. A nalysis of a central maxillary incisor by using a three-dimensional finite element method. J Oral Rehabil 1992;19:371-83.

10. Hubsch PF, M iddleton J, Knox J. A finite element analysis of the stress at the restoration-tooth interface, comparing inlays and bulk fillings. Biomaterials 2000; 21:1015-19.

11. M agne $P$, Douglas $W H$. Design optimization and evolution of bonded ceramics for the anterior dentition: A finite-element analysis. Q uintessence Int 1999;30:661-72.

12. Rees JS, J acobsen PH. The effect of interfacial failure around a class $\mathrm{V}$ composite restoration analysed by the finite element method. J Oral Rehabil 2000;27:111-16.

13. Sato $Y$, Shindoi N, Hosokawa $R$, T suga $K$, A kagawa $Y$. A biomechanical effect of wide implant placement and offset placement of three implants in the posterior partially edentul ous region. J Oral Rehabil 2000;27:15-21.

14. A kpinar I, A nil N, Parnas L. A natural tooth's stress distribution in occlusion with a dental implant. J Oral Rehabil 2000;27: 538-45.

15. H olmgren EP, Seckinger RJ, K ilgren L M , M ante F. E valuating parameters of osseointegrated dental implants using finite el ement analysis-a 2-dimensional comparative study examining the effects of implant diameter, implant shape, and load di rection. J Oral Implantol 1998;24:80-88.

16. Papavasiliou G, Kamposiora P, Bayne SC, Felton DA. Threedimensional finite el ement analysis of stress-distribution around single tooth implants as a function of bony support, prosthesis 
type, and loading during function. J Prosthet Dent 1996;76: 633-40.

17. Tanne K, M amoru S, Burstone $C$. Three-dimensional finite element analysis for stress in the periodontal tissue by orthodontic forces. A m J Orthod Dentofacial Orthop 1987; 92:499-505.

18. Geramy A . A Iveolar bone resorption and the center of resistance modification (3-D analysis by means of the finite element method). A m J Orthod D entofacial Orthop 2000;117:399-405.

19. Cobo J, A rguelles J, Puente M, V ijande M. D entoalveolar stress from bodily tooth movement at different levels of bone loss. A m J Orthod Dentofacial Orthop 1996;110:256-62.

20. M CGuinness $\mathrm{N}$, W ilson A N, J ones M L, M iddleton J. A stress analysis of the periodontal ligament under various orthodontic loadings. Eur J Orthod 1991;13:231-42.

21. Penedo ND, Elias CN, Pacheco MCT, de Gouvea JP. 3D simulation of orthodontic tooth movement. D ental Press J Orthod 2010 Sept-0 ct; 15(5):98-108.

22. Weltman B, Vig K WL, Fields HW, Shanker S, Kaizar EE. R oot resorption associated with orthodontic tooth movement: $A$ systematic review. A m J Orthod Dentofacial Orthop 2010 A pr;137(4):462-76.

23. Dong- $X u$ L, Hong-Ning W, Chun-Ling W, Hong L, Ping S, $X$ iao $Y$. M odulus of elasticity of human periodontal ligament by optical measurement and numerical simulation. A ngle Orthod 2011;81(2):229-36.

\section{ABOUT THE AUTHORS}

\section{Sagar S Padmawar (Corresponding Author)}

Student, Department of Orthodontics and Dentofacial Orthopedics M odern Dental Coll ege and R esearch Centre, Indore, M adhya Pradesh India, e-mail: padmawarsagar@yahoo.co.in

\section{Anup Belludi}

Professor, D epartment of Orthodontics and D entofacial Orthopedics KLE D ental College and Hospital, B engaluru, K arnataka, India

\section{Amit Bhardwaj}

Professor, Department of Orthodontics and D entofacial Orthopedics M odern Dental College and R esearch Centre, Indore, M adhya Pradesh India

\section{Vinay Vadvadgi}

A ssitant Professor, Department of Periodontics, Rural D ental College A hmednagar, M aharashtra, India

\section{Rajiv Saini}

Assistant Professor, Department of Periodontology, Rural Dental College, A hmednagar, M aharashtra, India 